\title{
Development Optimal Strategies for Media Policy of IRIB on Issue of Climate Change
}

\author{
Said Sarabi ${ }^{1}$ \\ ${ }^{1}$ Faculty member and assistant professor, Tehran broadcasting communication Collage, Iran \\ Correspondence: Said Sarabi, Faculty member and assistant professor, Tehran broadcasting communication \\ Collage, Iran. Tel: 98-91-2327-0669. E-mail: sarabyfr@yahoo.fr
}

Received: November 26, 2015

Accepted: December 3, 2015

Online Published: January 7, 2016

doi:10.5539/mas.v10n2p115

URL: http://dx.doi.org/10.5539/mas.v10n2p116

\begin{abstract}
The main objective of this research is developing optimal strategy for IRIB in relation to climate change. Arising Threats from climate change for human life and other creatures resulted in different media productions, all around the world. It is needed for IRIB to pay more attention to climate change problem in its programs, far more than current talk shows with experts. Achieving this goal with no strategy seems impossible.

In order to develop an optimal strategy for IRIB in relation to climate change, with the use of "in-depth interview" method, researcher provided the needed information from a couple of interviews with environment experts. With the use of in depth interviews, at first, current situation of climate change topic in IRIB, and then the responsibility of IRIB in relation to climate change were discussed. The next step was finding required information about climate change for a typical audience; this information is extracted from interviews with climatology and environment experts.

Using internal and external factors' analysis on IRIB performance on climate change, IRIB strengths, and weaknesses on subject and external threats and opportunities for IRIB in climate change topic were specified, and by the use of SWOT analysis all possible strategies were found. Finally the researcher found that optimal strategy for IRIB is an aggressive strategy.
\end{abstract}

Keywords: strategy, media policy, IRIB, climate change

\section{Statement of Problem}

Vital issue of climate changes according to dangers mentioned by climatology and environmental scientists need public attention and governments' announcements to people. Many attempts have been accomplished in analyzing probable climate change and global intention in fossil fuels consumption and emission greenhouse gases and pollutants since 150 years ago. One of the most precise studies suggests that heat has increased 0.3 to $0.6^{\circ} \mathrm{C}$ in global level since $19^{\text {th }}$ century. According to evidences, average increase doesn't happen similarly all over the world and some regions have experiences cooling in $20^{\text {th }}$ century. In recent 200 years, the average sea world class has increased 10 to $25 \mathrm{~cm}$. According to climate models, the average surface temperature of the world will increase 1 to $4.5^{\circ} \mathrm{C}$ since 2100 . In addition, it is expected sea world class increases 13 to $93 \mathrm{~cm}$ until 2100 (Babran, 2007)

The initial signs of climate exchange are to the extent that nearly all dwellers of earth can feel it and type of hierarchy can be seen in climate regulator of oceanic order system as storms, floods, forest firing, heat overflow, frequent droughts, and so on. Over all, the most important is extensive events and results of this occurring climate change that haven't been accomplished yet. (Ibid)

According to evaluations in enabling climate change program under supervision of United Nations convention on climate change using the proposed scenarios by Intergovernmental Panel on Climate change (IPCC), if CO2 concentration becomes twice since 2100 , Iran average temperature will increase 1.5 to $4.5^{\circ} \mathrm{C}$ which will lead to considerable changes in water resources, energy demands, agricultural productions, and coastal areas. Changes in temperature patterns, reduction water resources, increase sea level, destruction coastal areas, damage agricultural and food stuffs, destruction forest, intensification drought, and threat of human health are direct harmful effects of climate change. (Soleymani, 2005)

According to energy balance sheet in 2010, green house CO2 emission resulted from combustion in most 
economic sectors of Iran is more than other places in Middle East and sometimes it is several times more than other neighbors and same level countries. In addition, frequent and extensive droughts, intensive cooling occurrence, and generally uncommon seasonal changes, Gonu storm, and frequent floods in various geographical locations of state in several previous years, gradual consequences of these phenomena on farmers, and changing process of plant coverage in Iran various areas gradually have attracted state regulators and authorities to the importance of global threat and necessity for Iran attention to its participatory role and also it is expected IRIB to consider this issue seriously along with global village more extensively. Formation climate change convention in 1992 and consequently Tokyo protocol in 1998 necessitated searching for proper policies in countries who committed to control greenhouse gases. On the other hand, signature of the deceased Dr. Hassan Habibi, first deputy of IRIB that time president, on climate change convention (Rio de Janeiro, 1992) means a serious action by Iran toward reducing greenhouse gases and getting along with Iran with other signed countries in convention and environment defenders to have more favorite climate and better future for earth dwellers. Following by, climate change office and related research and scientific projects to environment protection were established in environment protection agency (EPA) in Iran in the same year and try to train experts by attempts of Dr. Mohammad Taghi Ebtekar.

Readiness against climate change needs participation of all nations and governments. In societies that people are aware more about this issue, inserted damages by this issue will be undoubtedly less. Attempts to make people aware of this issue in various state media leads to varied programs. For example, "documentation home" with private sector participation (PPR Company) in French was prepared by 12 million dollar budget in 3 years. This documentation was broadcasted all over the world freely and simultaneously by cinemas, Internet, DVD, and TV for addressees since Jun, 5, 2009.

This research tries to formulate favorite strategy for IRIB for this problem by getting environment experts' ideas and media to be able to provide favorite strategies according to occurring threats and opportunities for IRIB hoping to have next steps more serious and evaluated.

\subsection{Necessity and Importance of Research}

Climate change is one of confrontational problems for human in recent century. The importance of this issue is for its consequences that makes serious problems and dangers for environment and earth dwellers health. Continuity of this process make more serious problems occurrence in Iran. Iran, which is placed in low latitudes, will be one of countries mostly damaged by global warming which results in damage in agricultural sector.

Governments' role can be important and effective on public awareness from climate change. On the other hand, accurate informing and making environment culture by governmental media broadcasting are especially emphasized in clause A in article 64 of the fourth development program: EPA is responsible for ratifying related implementing regulations by ministers and suggestion of Supreme Council of environment along with accomplishment public awareness and achieving sustainable development to protect environment and emphasize on effective and prioritized groups of the fourth economic, social and cultural development plan of IRIB. All relevant systems and governmental media of IRIB are obliged to implement educational programs without considering issue of this legal article. Issue of climate change is such a problem which can hurt all society and readiness is tied with training all people and population participation. This research tends to work on how and what strategies can attract intention of public to this matter for IRIB and prepare them best by proper training to face with it.

\section{Research Purposes}

The purpose of this research is providing proper strategies for IRIB on issue of climate change by media to make culture and inform society to reduce state harms in this field.

The following secondary purposes are mentioned to get this general purpose:

1) What SWOT of IRIB should be concerned along with informing people about climate change according to media experts' points of view?

2) Evaluating proper strategies and select the best one.

\section{Questions of Research}

1) What are proper strategies of media for IRIB on issue of climate change?

2) What SWOT of IRIB should be concerned along with informing people about climate change according to media experts' points of view? 


\section{Conceptions of Research}

Policy: this term is translation the term "strategy" that is gotten from Greek root of "strategema" meaning army chief, combination of two terms of "stratus" which means army and "ago" which means leader. The conception of strategy first means adaptation and coordination forces to get to war purposes in army sciences. In other places, strategy is proposed as "strategy is collection of main purposes, policies, and general plans to get purposes to the extent of being able of determining such issues both what business and organization we want to work and what we want to do". "Chandler" used term of "strategy" for the first time and defined it as: "determination organization long-term purposes and selecting collection of actions and allocating necessary resources to get such purposes." (Chandler, 1962). For the first time, he indicated the difference between strategy and tactic in model of strategic decision definition (which deals with organization long-term health) and tactical decisions which are mostly related to daily activities. (Chandler, 1962)

Formulating strategy: it is identification effective external factors (opportunities and threats) on organization and also internal factors (strengths and weaknesses) of that organization, determination long-term purposes, intention to those factors, and determination proper strategies to obtain determined purposes.

Climate Change: according to definition of intergovernmental panel of climate change (IPCC), it is used for any change in climate during time even if this change is made by natural changes or as result of human activities (Babran, 2007)

\section{Educational Performance of Radio and TV in Society}

Education special rank is main performances of radio and TV. Radio and TV can extends educational-cultural clauses proper in internal boundaries of a country or in international level both by formal educational networks and inserting direct and indirect educational contents in their programs by which they get near to many educational purposes of human needs.

The importance of media educational responsibility is to the extent that some sociologists consider "parallel educational" or "permanent educational" role for press, radio, TV, and cinema. Sociologists believe that communicative instruments do educational responsibility beside teachers and professors by broadcasting new information and knowledges (Motamednezhad, 2002).

United Nations Educational, Scientific, and Cultural Organization (UNESCO) refer to 4 features for Radio \& TV, respectively:

1. Programs as a sequential collection to help to better learning.

2. Designing and programming them clearly by educational counselors.

3. These programs are usually beside other educational cases such as text books, and guide books.

4. Using these programs is evaluated by teacher and student typically. (Dadgaran, 1995)

\section{Research Theoretical Framework}

\subsection{Knowledge Gap Theory}

Tichenor, Donohue, and Olien proposed knowledge gap theory. They defined gap conception as: beside mass media informing in a social system, people of high economic rank and low-economic rank are both informed but people of high-economic rank get more information, so knowledge gap increases instead of decrease between these 2 groups. "In other words, the main knowledge gap theory indicates that society sectors with high economic rank get information faster than low economic rank when a society is informed more." (Severin \& Tankard, 2002)

Moreover, studying about knowledge gap shows that in sophisticated issues such as energy, prosperous people get their information from media (newspapers), while less prosperous people get their information from other media (TV broadcasting). These findings show that information campaign planners need to study about addressees and addressees benefit from selecting various media to access to various parts. Eventually, as "Drouin" mentioned, informational campaigns probably should start from needs of potential information users. (Ibid)

\section{Criticism of Knowledge Gap Model}

Drouin criticizes knowledge gap model, because it doesn't efficiently cover pivot. This model is based on extract awareness as a criterion neglecting this reality that people create their awareness and meanings themselves. Knowledge gap is meaningful for researchers but it may not seen in this manner according to addressees' idea. Addressees search information which they need in real time and place situations and don't concern to important and significant issues according to researchers and other observers. Drouin talks about another gap observing with imagination in mind and discerning sense that needs to adjust its movements in its life. Therefore, an 
important criticism about knowledge gap is that people search for information which seems important to them. Knowledge gap is just made by observers as it is talked in this research.

\section{Solutions for Knowledge Gap Theory}

Rogers suggests solutions in 3 classifications:

A) It is better inform people more attractively with low economic rank; although, it may be unattractive for high economic rank people.

B) Specified communicative channels of deprived people should be used.

C) Some low economic rank people resemble to discuss and talk about innovations.

D) Attempts on changing should be concentrated on lumbered and late people and prevents from adopters.

2-When elite groups get more information than the peer low-economic group:

A) Leaders of low-economic group inform them.

B) Use the same row factors in lower groups.

3-When elite groups have more stationary resources than low economic group to follow innovation message:

A) Suggest innovations and behaviors corresponding to economic and social rank of weaker people.

B) Let deprived class of society to implement and participate in program. (Razzaghi, 2002)

\section{Theory of Framing}

Frames are main and infrastructural cognitive structure determining reality perception and provision and help a person to interpret his world. In this regard, frames can be known as cognitive schemas influencing on our perception and understanding (Mahdizadeh, 2010)

Framing is media content selected control process by media authorities and stated how specific part of media or resulted meaning is provided in a package to provide various favorite interpretation. Framing refers to the relationship between context and information to the way it reflects specific meaning to mind. Therefore, this theory emphasizes on organized information based on a certain pivot.

Media provide defined and certain cognitive structure for addresses so that their conceptualization from surrounding and perception of reality is based on media framing.

Referred to 2 frames by providing a process pattern about framing: first, "media framework" and second "personal frameworks" (receivers).

D. Scheufele made conceptual differences between media frameworks and personal frameworks following kinder and Sanders (1990). Kinders and Sanders announce that frameworks can act both as "political tricks in political discourse" and "mind internal structures".

According to D. Scheufele pattern, there are four relevant framing processes: first, construction of using media frames by journalists and other news employees who are regularly impressed by resources, values, and news angles to report events. Second, transferring proper news reports to addressees by media frameworks. Third, accepting these frameworks. Fourth, consequence of media framing for attitudes, views, and behavior of addressees. (Mahdizadeh, 2010)

Actually, media frames events and issues as a photographer assembles photos' frames, selects an interesting piece, and put away other pieces. Media framing process is similar to building a frame for house proper to what inside it. Communicator selects a frame of a structure in appropriate to his message content.

Media uses policies such as selecting words, metaphors, allusions, and allegories. In addition, part of framing is "detachment" of communicator from events so media can "regenerate content" of event.

\subsection{Studied Society of This Research}

9.1.1 Studied People in This Research Are as Following:

Teachers and communication professionals, psychologists, media and strategic management, sociologists, environment, geography, and meteorology professors and experts.

\subsubsection{Sampling Method}

Sampling method of this research is non-random purpose-built. 


\subsection{Determining Sample Volume}

We continue constant samples for qualitative and in-depth interview methodology until we get to information saturation. In this research, 29 members were interviewed from society.

\section{Data Collecting Instrument}

Data collection instrument in this research is using voice recorder or note-taking from studied society.

\section{Research Validity and Reliability}

The validity of this research is formal (by referring to experts and professors). In formal method, the proposed questions are given to authors and experts to express their ideas explicitly. In this step, the proposed questions are investigated several times in this field and consequently necessary changes are inserted in questions and reconfirmed by relevant experts and professors.

Since this research is qualitative, it doesn't claims on generalization results.

\section{Implementation and Analytical Method}

Methodology of this research is in-depth interview. This research was done by initial interview which was prepared openly in the first step and given to experts. After collecting responses, by investigating confirmation and repetition title by experts, the most important SWOT, landscape, and emission for IRIB were determined. Since obtained data from questionnaire of first step is very high and incoherent, questionnaire of the second step was given to experts to determine the most important landscape and emission of SWOT by attributing rank and coefficient. After collecting questionnaire in the second step and calculating obtained scores from determined rank, coefficients, or each one, average score for each SWOT points were obtained and favorite strategies was made by SWOT analysis matrix. In the third step, first step SWOT and obtained strategies of the second step were used to obtain each strategy. For this purpose in the third step, giving attraction score to each SWOT points was obtained by calculating attributed average score to each one and final attraction score was obtained for each case according to obtained coefficients in the second step which obtained strategies priority for IRIB was indicated by calculating final attraction scores sum for each strategy.

\section{Research Findings}

\subsection{The Most Important Strengths}

- Possibility of playing the central role by IRIB about climate change in state.

- Coordination of this issue with environmental and media centers along with macro purposes of Iran government

- Possibility of using national media and province networks for better conception of environmental problems of each province by native network of IRIB government.

- Possibility of using broadcasting networks for better coverage of this problem for various social levels of specific addressees with network emission.

- Possibility of low-cost and effective advertisement for children, teenagers, and adults in this field in schools and universities with cooperation of environment organization.

\subsection{The Most Important Weaknesses}

- Unattractive advertisement of climate change for children and teenagers

- Hardship of scientific issues about climate change for general addressees of country.

-Non-perception importance of climate change by some authors of Iran government.

- Ruining scientific content and message of program about climate change while changing it to an attractive radio and TV program and even movies.

- Inadaptability with responsible governmental agencies.

\subsection{The Most Important Opportunities}

- Using national and religious culture richness in IRIB media policy.

-Using climate change in media diplomacy

- Using governmental and NGO organization training for general relations authors, employees, and governmental authors.

- help to satisfy national role in reducing greenhouse gases 
- Using specific budget of international responsible institutes on climate change issue

\subsection{The most important Threats}

- Not prioritizing environmental issues and climate change for a part of general addressees.

- not using of national media from programming native pattern and Iranian-Islamic life style while using foreign dubbed programs and all-aspect non-cooperation and non-adaptation of national media with IRIB government (as national media is not under authority of president and government).

- Lack of water and drought in Iran and dryness of Hamun River in Sistan and Baluchistan, Bakhtegan in Fars province which inserts long-term irreparable consequences on Iran plateau ecosystem.

- $90 \%$ of agricultural water is wastes according to recent statistics of agriculture Jihad ministry which is a potential threat for Iran agriculture and Iran plateau ecosystem.

- Non-serious importance of state universities of climate and lack of all-aspect cooperation with agriculture jihad and ministry of power.

\section{Conclusion}

- Favorite emission of IRIB government on issue of climate change which includes:

Increase in all-aspect cooperation of people and governmental authors to remove or reduce the maximum problems and damages of climate changes.

- Favorite landscape of IRIB government on issue of climate includes:

Maximum increase or decrease damages or climate changes, people permanent cooperation and government authors about this issue.

- Favorite purposes of IRIB government on issue of climate change include:

1- Institutionalization anxiety of maximum reduction or removal of problems or climate changes damages on people.

2- Permanent and continuous cooperation between people and IRIB government for maximum reduce or removal of problems and climate changes damages.

- Four classes of policies from SWOT matrix analysis were obtained for IRIB government about climate changes that aggressive strategies were discerned by scoring internal and external factors of prior policies experts: aggressive strategies are observable well in the following table; ( 2.5 is principle number which means that if all SWOT scores becomes more than this number, studied strengths or opportunities increase and if becomes less than number, studied weaknesses or threats increase. (Arabi, 2006, 56)

\begin{tabular}{lcll}
\hline Score & 4 & Conservative & Aggressive * $(\mathrm{X}=2.575 \& \mathrm{y}=2.334)$ \\
External factors & 2.5 & Offensive & Competitive \\
& 1 & 2.5 & 4 \\
\hline & Score of internal factors $(\mathrm{X})$ \\
\hline
\end{tabular}

- Aggressive Strategies include:

Fist Strategy:

- attracting financial supporters among foreign responsible organizations, attracting governmental and NGOs participation to improve climate change programs' contents, make dynamism (campaign) for climate change, and alert people.

-Second Strategy:

- making radio, TV, and meteorology networks or attributing specific time of the present networks of broadcasting to meteorology, climatology, and climate change.

A- Criticism and experts programs related to climate change and environment

B- Producing province programs by emphasis on changes in the same province climate.

C- Proposing various aspects of this issue in specialized network according to mission and type of broadcasting addressees.

-Third Strategy: 
- establishing meteorology website in internet and receivable virtual space in cell phones to train meteorology, climatology, and climate change to children, teenagers, and adults in kindergartens, schools, and universities.

-Fourth Strategy:

Making all-aspect cooperation and coordination of education administration, sciences, researches, and technology ministry, Islamic guidance, and culture ministry with agricultural jihad and ministry of power for all Iranians.

Prioritization aggressive strategies for IRIB climate change issue is based on their attractions according to experts ideas in the following table:

\begin{tabular}{lll}
\hline Priorities & Strategies & Total score of attraction \\
\hline First priority & Fourth strategy & 4.612 \\
Second priority & Third strategy & 4.271 \\
Third priority & Second strategies & 3.981 \\
Fourth priority & First strategy & 3.459 \\
\hline
\end{tabular}

First priority:

All-aspect cooperation and coordination of education ministry, sciences, researches, technology ministry, culture and Islamic guidance ministry with power ministry, agriculture jihad, and environment protection agency in making culture and informing issue of climate change for all Iranians.

Second Priority:

Making a meteorological website in internet and connecting virtual space in intelligent cell phones to educate meteorology, climatology, and climate change for child, teenagers, and adults in kindergartens, schools, and universities (making environment protector campaign among teenager and adults)

Third Priority:

Making meteorological radio and TV networks or attribution specific time of the present broadcasting networks to train meteorology, climatology, climate change.

1- Producing critic programs and related investigation on climate change and environment

2- Producing province programs by emphasis on occurred changes in the same province climate.

3- Proposing various aspects of this issue in specific channels by attention to emission and addressees of that broadcasting network.

Fourth Priority

Attracting financial supporter among foreign responsible organizations, attracting governmental, and NGOs participation to train employees, counselling with them to improve programs content of climate change, and making dynamic campaigns for climate change and informing people.

\section{Suggestions}

- Research on identification increasing information of government authors and employees of IRIB from important environmental issues and climate change.

- Studying facilitating methods for cooperation the author organizations of environment with IRIB broadcasting

\section{References}

Babran, S. (1386). Climate change, environmental challenges of the twenty-first century. Tehran, Expediency Council, Strategic Research Institute, Department of International Studies.

Bahonar, N. (2006). Media and religion. Tehran: IRIB Research Center.

Britain, F. (1998). Media theory, (Mahmoud Kashani fact, Translator). Tehran: Research, studies and evaluation of the IRIB program, first printing.

Chandler, A. D. (1962). Strategy and Structure. Massachusetts: The M.I.T.

Dadgaran, S. M. (1995). Principles of mass communication. Tehran: Morvarid pub.

Damon L., Thomas R., \& Taylor, B. T. (2009). Qualitative research methods in communication sciences. (Doctor Abdullah Givi, Translator). Tehran: the Institute for Citizen. 
David, F. R. (2006). Strategic management, (doctor Ali Parsaeian, and doctor Mohammad Arabi, translators). Ninth edition, Tehran: Office of Cultural Research.

Ehrenberg, A., \& Barvayz, P. (1999). TV and its addressees (Farhad Radpour, translator). Tehran: IRIB broadcasting, program evaluation researching center.

Ghassaban, H. (2005). The structure of television documentaries-with satisfaction approach addressed to them in the area of reducing air pollution. Master's thesis, Department of Broadcasting, Tehran.

Karimi, D. (2003). Education and sustainable development. Proceedings of the World Summit on Sustainable Development, Tehran, Iran: Kian Mehr.

Karimi, D. (2008). Environmental strategies for increasing knowledge of and seeking participation of citizens in Tehran. Tehran Metropolis Conference environmental challenges and strategies, printing, Tehran: Tehran Urban Planning Center.

Lashkarboluki, M. (2007). Free interpretation and application oriented content Bryson, Stacy and Ansoff management on strategic issues. Retrieved February 5, 2012, from http://mojtabaonline.com

Mahdizade, M. (2010). Media theories: common ideas and critical views. Printing, Tehran: Hamshahri.

Marshall, K., \& Rasmann, G. (1381). Qualitative research methods. (Doctor Ali Parsaeian and Doctor Mohammad Arabi, translators). Tehran: Cultural Research Bureau.

Mc Quail, D. (1382). Introduction to Mass Communication Theory (P. Ejlali, Translator). Tehran: Center for Media Studies \& Research.

McBride, S. (1996). A world of multiple audio (I. iPod, Translator). The second edition, Tehran: Soroush.

Mohsenian, R. M. (2003). Its geology. Fifth Edition, Tehran: Soroush.

Motamednejad, K. (2002). Mass media. Tehran Allameh Tabatabai University Press. Basic concepts of climate change. Retrieved November 20, 2012, from http://www.climate-change.ir/fa/concept

Nasiri, B. (2005). Alternative media. Retrieving January 1, 2012, from http://www.bashgah.net

Nekuei, S. (2010). Islamic Republic of Iran Broadcasting role in increasing audience awareness, reduce air pollution (from environmentalists and the media). Master thesis, Faculty of television, Tehran.

Office of Legal Affairs of the Parliament. (2004). Rules and regulations of environmental protection. Volume I, Second Edition, Tehran: Environmental Protection Agency.

Orabi, M. (2011). Mosque indexes ideal strategy from the perspective of the religious elite, using the SWOT model and gap analysis (case study: the mosques of Tehran). Master's thesis, Faculty of Social Sciences of Payam Noor University, Tehran. Retrieved January 1, 2012, from http://www.doe.ir/Portal/Home/Default

Pakdel, H. (2008). Iran's Press TV television for optimal strategies. Master's thesis, Faculty of IRIB, Tehran.

Razzaghi, A. (2006). Theories of social communication. The second edition, Tehran Asim publication.

Sadeghi, H. (2007). The virtual world of television, media conference proceedings, television and secularism. Qom: Daftar Aghl.

Severin, W., \& Tankard, J. (2007). Communication theory (Dehghan, Translator). Tehran: Tehran University.

Soleymani, J. (2005). The effect of greenhouse gases. Book of the Month Science and Technology, No. 87 and 88.

Spiggle, J. (1994). Analysis and interpretation of qualitative data in consumer research. Journal of consumer research, 21, 491-503. Retrieved from http://www.homethemovie.org

Vindal, S., \& Olson, J. (1997). The application of communication theory (Dehghan, Translator). Printing, Tehran: the Center for Studies and Media Research.

Wimmer, R. D., \& Joseph, R. (2005). Research into the mass media (Kavoos Seyed-Emami, translator). Tehran: Soroush.

\section{Copyrights}

Copyright for this article is retained by the author(s), with first publication rights granted to the journal.

This is an open-access article distributed under the terms and conditions of the Creative Commons Attribution license (http://creativecommons.org/licenses/by/3.0/). 